\title{
CULTURE SHOCK EXPERIENCED BY FOREIGN STUDENTS STUDYING AT INDONESIAN UNIVERSITIES
}

\author{
Dwi Poedjiastutie \\ University of Muhammadiyah Malang, Indonesia
}

\begin{abstract}
This study was designed to examine the potential culture shock experienced by foreign students in Indonesian university. There were 10 foreign students who responded to the questionnaires sent by the writer through BIPA (Indonesian for foreigners) in international office of foreign students' universities. It was found that there were three points of academic life that make foreign students experience culture shock, namely: teacher's roles and attitudes; poorly organized programs; and the local students' attitudes. In social life, it was found that foreign students experienced culture shock in 3 aspects, namely: women-men relationships; different ways of thinking and different habits.
\end{abstract}

Key words: culture shock, foreign students

In the year of two thousand when the Indonesian government establishes the program of Dharmasiswa, many foreigners from all over the world come to this country to learn Bahasa Indonesia. Dharmasiswa is a scheme offered to students all over the world to study Indonesian language and culture in Indonesia. More and more students from various races and cultures study in this country. Foreign students are placed in some universities in Indonesia. The diversity in the student population will affect pattern of interaction between teachers and foreign students, between local students and foreign students. Teacher who interacts with the students from the same culture with her/him might experience less cultural problems. But when teacher and students hold different views of cultural norms appropriate to particular situation, it is not difficult for misunderstanding to occur. With the establishment of Dharmasiswa programs, the university academic atmospheres change. Teachers nowadays are not only demanded to deliver teaching materials but also to equip themselves with cultural 
knowledge so that they might be as the source of help if the foreign students experience difficulties adjusting into the new culture.

A research had been carried on to examine educational and cultural problems experienced by overseas students from non English speaking backgrounds at Australian universities (Samuelowicz, 1987; Bradley and Bradley, 1984). However, a few researches tried to reveal culture problems experienced by foreign students studying in Indonesian universities since Dharmasiswa program is relatively new and at first only a few numbers of foreign students attending this program. Year by year the quotas increase. Now there have been significant numbers of foreign students attending Dharmasiswa program in Indonesian universities. Since many people from different nations come to learn in Indonesian academic context, Indonesia should be aware of the potential cultural shocks. These potential problems should be identified and minimized in order to give the foreign students and the local people an atmosphere of mutualism and understanding. Therefore, this study tried to identify the culture shocks experienced by foreign students during their direct contacts with the local people.

\section{METHOD}

An open-ended questionnaire was developed for the purpose of the study and was distributed to all Dharmasiswa students studying in some universities in Malang. There were four universities in Malang appointed by the government to take in charge of the Dharmasiswa program, namely: Universitas Negeri Malang (UM), Universitas Muhammadiyah Malang (UMM), Politeknik Negeri Malang (Poltek), and Vocational Education Development Centre Malang (VEDC). Each university had different numbers of foreign students under Dharmasiswa Program. The writer with the help of BIPA (Bahasa Indonesia bagi Penutur Asing) centers of each university obtained the contact person of foreign students. There were 10 foreign students who responded to the questionnaires sent through BIPA in the foreign students' universities. It had been stated clearly on the questionnaire that the foreign students' participation was voluntary but strongly recommended since the number of foreign students in Malang in the year of 2008 was not very big. However, only ten out of twenty five foreign students in Malang returned the questionnaire and therefore, 10 foreign students were included in this study. All ten respondents were from English Speaking Countries. There were 7 (seven) from Australia, 1 (one) from Hungary, 1 (one) from Germany, and 1 (one) from Poland. 8 (eight) of them 
are females and 2 (two) of them are males. The respondents aged from 21 to 29 years old. It means that the respondents were equal to undergraduate to graduate level students. They stayed in Indonesia for one year and had never been in Indonesia before. One respondent was born in Indonesia but she/he grew up in Germany. Some points revealed and asked in the questionnaire were:

1. the academic differences between respondents' country and Indonesia that make them difficult to adjust

2. the social life differences between respondents' country and Indonesia that make them difficult to adjust

Each subject completed questionnaire individually at his or her own convenience. Name and addresses were not required on the questionnaires in order to encourage the respondents to give sincere answers. However, they were asked to give personal information only such as: age, sex, and nationality and the academic year of the students' university entrance.

The obtained data were analyzed qualitatively as well in the form of narrative presentations. Everything was presented as it was. The data and responses were neither subtracted nor added to maintain the originality of the story. The next step was to find out the respondents' common answers then to create classification. If the respondents' answers had a great variety and proved inconsistent one another then the data was presented as it was.

\section{FINDINGS AND DISCUSSION}

\section{Academic Differences between Indonesia and Foreign Students' Countries}

The academic problems faced by foreign students fell into three categories, namely: teacher's role and attitude, poorly organized program, and local students' attitude.

\section{Teacher's Role and Attitude.}

Many respondents complained that some Indonesian teachers in their course did not attend to the classes with clear reason; such rarely happened in the foreign students' academic context. Moreover, the teacher's role in respondents' countries was much more as facilitator who facilitated the students' learning and discussion. In respondents' academic context, the students were supposed to take an active participation and responsible for their own learning. This was the opposite of the academic system in the respondents' host universi- 
ties. As a result, when they came and studied in Indonesian context, the academic adjustment should be made. The followings are taken from the respondents:

Lack of structure of subjects, plagiarism is common practice so is buying assignments. Lecturers are not turning up to classes. In Australia, we have lecturers and tutorials for each subject. Tutorials are small group discussion with 15 or so, students led by a tutor or lecturer.

The fact that lecturers sometimes do not come to class. The lack of reading materials. Lack of information about assessments. Lack of students' participation in classes. These aspects made me frustrated with academic life here.

In Indonesia, the lecturers are frequently absents, something which almost never occurs in Australia. In my country it is also common practice to give very specific schedules to students and to outline clear expectation. In Indonesia, some lecturers do this, others do not. In Australia, It is also more research based.

As above, but not difficult to adjust to. Sometimes the lecturers do not go to class and you have spent half a day waiting for it. Yes, the gap between teachers and students is wider. Lecturers seem less available for consultation, less student participation in classes.

\section{Poorly Organized Program}

Poorly-organized program and classroom organization were the major complaint to the respondents. Almost all respondents said that they got frustrated dealing with classroom organization since there were many aspects that they did not know and did not know what to do. The poorly organized program meant there were no clear and specific information about where to get books and references, when the tests are given and conducted, and when the assignment was due. Besides, there was no clear schedule, subject descriptions, and syllabus, rules and regulations. The followings are derived from respondents' opinions:

Not knowing where to get text books from, when tests are on, or when assignments are due. The lack of clarity of information about these things given to students can be difficult at times. 
I know from my relatives that the atmosphere in a university is more serious and students are treated as a grown up/adult. The requirement is higher than in Indonesia.

In terms of academic life, I haven't encountered any serious difficulties yet. Maybe this goes only for Dharmasiswa program, but the organization is not too good and sometimes seems to be chaotic.

The fact that lecturers sometimes do not come to class. The lack of reading materials. Lack of information about assessments. Lack of students' participation in classes. These aspects made me frustrated with academic life here.

In Indonesia, the lecturers are frequently absents, something which almost never occurs in Australia. In my country it is also common practice to give very specific schedules to students and to outline clear expectation. In Indonesia, some lecturers do this, others do not. In Australia, It is also more research based.

\section{Local Students'Attitude}

Local students' attitudes were also another difficulty that foreign students had to adjust. Foreign students wanted to listen attentively on that lecture but they were distracted by the noises made by some local students. In addition, many local students might comment rudely on the foreign students' existence as if the foreign students were strange creatures.

Mainly language and cultural difficulties, such as a very relaxed approach to teaching and learning that often means students talk over the lecturers. Sometimes, it seems students are only there to socialize and university has become a kind of status symbol

A lot of people stare at me in Indonesia and yell funny comments, I understand that they are being friendly but it is still very different than in Australia.

Indonesian students are very loud. Sometimes they run in the corridor, make a lot of noise without taking into account the fact that other people have classes at that time. It happened to me that I couldn't hear my teacher (and the classroom was closed!) because of the students playing outside.

\section{Social Life Differences between Indonesia and Foreign Students' Coun- tries}

In addition to academic shock, social shock experienced by foreign students was also revealed. Social life covered broad aspects but only experiences 
came from respondents were presented. In this study, the social shocks fell into three categories, namely: women-men relationship, the degree of community bonding, and gathering habits.

\section{Women-Men Relationship}

The respondents almost have common opinion on women-men relationship in Indonesia. According to them, women-men relationship in their country was more open than in Indonesia. When girls and boys went out together, it did not necessarily involve romantic feeling. They can be just friends. In Indonesia, in contrast, two friends of the opposite sex went out together were usually considered as lovers.

People are less individual in Indonesia, constantly surround themselves with others. In Australia, girls surely do things on their own. Most social events do not involve alcohol. In Australia, girls and boys often hangout together when they are just friends. In Indonesia, it seems that indicates 'pacar' status.

Yes, especially for female-male relations are a lot more open in Australia.

People interact more on a one on a one basis in Australia, and there is more interaction between boys and girls at the friendship level

Yes. Social life in Australia is based more on long-term friendships and occasions are more often than not celebrated with a drink. In Indonesia, making friends is easy, almost too easy, and it can often be hard to realize who actually your friend is or who simply wants to hangout with a 'bule'.

\section{Community Bonding}

Some respondents said that in Indonesia a bond among family members, between friends and friends, and within community were very strong. On the other hand, in the respondents' country of origin, people might do anything they want and like without much interference from family, friends, and community.

Because so many students live close to campus and away from their families there is a stronger bond between friends and people will participate in many more social activities.

I have more of a social life in Indonesia. Everyone lives close together and can hangout all the time. In Australia there is no time to do this all the time. 
Yes. Here in Indonesia, people are friendly and open. Taking chances every moment to make connection with other people from foreign countries like me. In my country, people are individuals and closed. They don't care about other people.

There are a lot of differences in social life. While social life in Indonesia seems to be based on a strong community feeling, it is more individual focus in Germany. People in Germany usually don't ask you about your religion or if you are already married. For me as a woman, it is not always as comfortable to behave the way I used to in Germany (e.g. smoking in public, going out alone when it's already dark) And sometimes it feels as if people- especially older people look down on me.

People are less individual in Indonesia, constantly surround themselves with others. In Australia, girls surely do thing on their own. Most social events do not involve alcohol. In Australia, girls and boys often hangout together when they are just friends. In Indonesia, it seems that indicates 'pacar' status.

\section{Habits in Social Gatherings}

Some of the respondents said in Indonesia the social gathering did not involve drinking activities. However, in the respondents' country of origin, it is common that social gathering involves alcohol.

People are less individual in Indonesia, constantly surround themselves with others. In Australia, girl surely do thing on their own. Most social events do not involve alcohol. In Australia, girls and boys often hangout together when they are just friends. In Indonesia, it seems that indicates 'pacar' status.

In general, the social life is similar. It is based on meeting friends, chatting, hanging out together, eating out together, etc. The difference is that in my country young people go out at night and often drink some alcohol (beer for example).

\section{DISCUSSION}

\section{Academic Shocks}

In academic atmosphere, foreign students stated that the teachers' role and attitude, poorly-organized program and the local students' attitude made foreign students shock. This finding supports the theory that both Eastern and Western countries have different academic systems. Eastern educational system 
mostly emphasizes a reproductive and conservative attitude to knowledge, teachers play central roles in the teaching learning process and are expected to provide all knowledge that students need in their course. The teachers' attendance in the classroom indicates that teaching learning activity occurs. Furthermore, a good teacher in most Eastern cultures should provide lecture summaries, revision notes, even model answers to typical exams questions. On the other hand, teachers in most Western countries are not the sole source of information for the students. They tend to employ a discussion method and focus on problem solving. Prior to entering the tutorial, teachers usually bring problems to discuss and encourage students to think about alternative solutions rather than giving the learner ready-made answers. According to Su and Goldstein (1994), in academic system variation of teacher's and students' roles and teacher's and students' attitudes are not merely product of variety of activity in classroom instruction but also the product of culture. The different roles of teachers are the most significant features in both Eastern and Western cultures.

Another thing characterizing Eastern academic system including Indonesia is the learners are mostly passive recipients who accept the information, jot it down, memorize it, and recall it for the examination (Ballard and Clanchy, 1991). They wait to be judged on whether or not they have focused their attention on the teachers' information. Learners are not encouraged to ask questions, to express their opinions of the given information. If they can remember correctly most of the information, they are considered good learners who deserve to pass examination. However, in English-speaking-country contexts students' direct participation of classroom discussion is emphasized. Students are allowed to challenge and question the teachers' information; learners are encouraged to be individual, creative, and independent. Therefore, it is common in Western classroom for teachers to be confronted with the students' different opinions. Even though it is argued elsewhere that the different cultural and educational system may determine the different approach to learning, both Eastern and Western students showed their learning achievement. Biggs (1996) produces evidence in his study that some Asian students not only have deeper approaches to learning but also significantly outperform Western students in many areas.

Cultural traits may contribute to shape the learners' attitude to learning. Many research findings have recently challenged the stereotypes of Asian students. However, Ramsay et.al (1999) discovered that both Eastern students and Western students undergo positive and negative critical incidents which im- 
pacted upon their learning in the first year of their university level. It is understandable that foreign students find themselves studying in situation where the learning context is different from their previous experiences. They attempt to respond to the academic life that they might not have come across before such as frequently absent teachers, lack of information about assessments, the lack of reading materials, and lack of students' participation in classes, no specific schedule, and no clear expectations of the courses. Since foreign students may have come from educational contexts that appreciate independent thinking and active participation, their customary learning strategies suddenly have to be replaced by the approach with more regulation from the teachers. They may face a series of difficulties to deal with the new situation where teachers behave differently when compared with the behavior of teachers in the countries from which they came.

\section{Social Shocks}

In social life, it was found that foreign students experienced culture shock in three aspects: women-men relationship; community bonding, and different habits. This finding is in line with the theory that the social life differences were rooted from collectivism-individualism cultural based values. Indonesian cultures valued and centered on collectivism while English speaking countries valued on the liberalism and individualism. Collectivist cultures have been described as valuing goals and interests related to the cultural group while individualist cultures tend toward personal goals and tasks (Triandis, et al., 1988; Hall, 1966). More specifically, collectivist cultures are viewed as communal, interest sharing, harmonious and face supporting. Individualist cultures have a tendency to emphasize the needs, interests and goals of the person; thereby signaling a greater need for personal space, distance, and privacy (Triandis, et al., 1988; Hecht, Anderson \& Ribeau, 1986). Culture shock is relatively short term feeling of disorientation, of comfort due to unfamiliarity of surroundings, the lack of familiar cues in the environment. Culture shock occurs to almost all people who cross over cultural boundaries, whether they have done so voluntarily or not. According to Martin and Nakayama (1999), there are four pattern of cultural adaptation: marginalization, separation, integration, and assimilation. Marginalization occurs when the individual or group expresses little interest in maintaining cultural ties with host culture. Separation is when individual or group willingly to choose to retain their original culture and at the same time avoid interaction with other groups. Integration occurs when people have an in- 
terest in maintaining their original culture and also in maintaining daily interaction with other culture. And in the assimilation mode, the individual does not want to maintain an isolated cultural identity but wants to maintain relationship with other groups in the new culture. For many individuals the long term adaptation is not easy. Some people actively resist assimilation in the short term. However, since most of respondents' length of stay was averagely one year, the pattern of culture adaptation was integration. The respondents' pattern of adaptation is not yet called assimilation. In an assimilation mode, the individual does not want to maintain an isolated cultural identity but wants to maintain relationship with other groups in the new culture. The assimilation process will occur to individual depending on several factors such as the length of stay in the host culture, and individual personality. Hofsede (1997), Hetch, Collier \& Ribeau (1993) argue that students who have predesposition for collectivist values have more difficulty adapting to American culture than students with a predisposition for individualist values. Hofsede's argument was not completely true. Respondents in this study have a predisposition for individualist values also experienced difficulties adapting to Indonesian cultures. They were shocked when especially local people did not involve drink in social gathering and when local people try to make intensive interaction with them as foreigners.

\section{CONCLUSIONS AND SUGGESTIONS}

The result of this study indicates that foreign students studying in Indonesian context experience culture shock. The responses vary from confusion, disappointment, frustration, to depression sometimes the withdrawal from the new culture itself. Being aware of the differences that exist between cultures and knowing how to act when they face with puzzling cross-cultural situations are very important skills for harmonious intercultural relations.

It is strongly recommended that foreign students who are going to come to this country should join the pre-departure program. This pre-departure program is usually offered in their home country or the host country. This program will equip the students with language training or cross cultural understanding training so that they will get the right information how to behave in their host country and be ready with cultural adaptation process.

The host institutions should involve the local students to welcome the foreign students so that the cultural exchanges occur. The local students might learn the new way of life and the way of thinking from foreign students and the 
foreign students do too. This way will help people from different context understand each other and in the long run it will help them to learn of being more tolerant. Welcoming program can be established from the first stage of the foreign students' arrival such as the airport pick up, to familiarize with the transport system, shopping system, banking system, university's facilities, renting house system, visiting cultural sites, and many more.

In academic world, it seemed that in one side Indonesian government is eager to welcome and promote Indonesia in more international and global context but in the other side, the government did not seem to be ready to set structured, well-planned program as well as apparatus. The foreign students' comments above not only refer to the different academic system but also to poorlyorganized program. Before the introduction of particular programs offered for international, the institution is suggested to set up distinctive, clear, and structured programs. The clear agenda should have been discussed among related units and departments within the institution and external institutions. The clear agenda include: the purpose of foreign students coming to Indonesia, the departments they are going to choose, the availability of resource persons, the contact persons or the institution of their initial coming to the Indonesia, the availability of peer supports, the campus orientation program, language and cultural training and it should be companied by fixed and clear schedules. There are many things merit considerations as well such as the commencement of the study, class schedule, lecturer, subject and lesson guidelines, resource person or academic advisor, the availability of liaison officers where foreign students can contact this units anytime they want to get the information and experience difficulties. Furthermore, the questionnaire can be distributed before, during and after the program to get feedbacks, inputs, and ideas of the foreign students' expectations, perceptions of the running programs. Before the program, the questionnaire might ask the foreign students expectation of coming to this country and the things that they might learn and take by attending the program. During the program, the questionnaire might explore the students' opinions of the running program. The difficulties they might encounter in attending this program, and whether the program offered have been implemented and satisfied. After program questionnaire might ask foreign students to give feedback and inputs of the running program. It is very essential for the institutions to plan, organize, establish and evaluate the program so that the improvement can be planned and achieved. 


\section{REFERENCES}

Bradley, D. \& Bradley, M. 1984. Problem of Asian Students in Australia: Language, Culture, and Education. Canberra: AGPS

Brislin, R.1993. Understanding Culture's Influence on Behavior. Fort Worth, IX: Harcourt Brace Jovanovich.

Dinges, N. 1996. Intercultural Competence. In D. Landis \& R. Bhagat (Eds), Handbook of Intercultural Training. Thousand oaks, CA: Sage.

Hall, E.T. 1996. The Hidden Dimension. Garden City, NY: Doubleday.

Hecht, M.L, Collier, M.J, \& Ribeau, S.A. 1993. African American Communication: Ethnic Identity and Cultural Interpretation. Newbury Park, CA Sage.

Hofstede, G.1997. Cultures and Organization: Software of the Mind. New York: McGraw-Hill.

Kim, Y.Y.1995. Cross Cultural Adaptation: An Integrated Theory. In R.L Wiseman (Ed), Intercultural Communication Theory (International and Intercultural Communication Annual 19). Newbury Park, CA: Sage.

Martin, J.N \& Nakayama, T.K. 1999. Intercultural Communication in Context. California: Mayfield Publishing Company.

Miyamoto, Y. \& Rasmussen, R.1998. 'The Effectiveness of a Japanese Language Course on Cross Cultural Competence'. JOLIB 9 (1)

Samuelowicz, K.1987, Learning Problem of Overseas Students: Two Sides of a Story. Higher Education Research and Development, 6 (2).

Triandis, R., \& C. Harry Hui 1988. Cross Cultural Training Across the Individualism-Collectivism Divide. International Journal of intercultural Relation 12. 